\begin{tabular}{|c|c|}
\hline 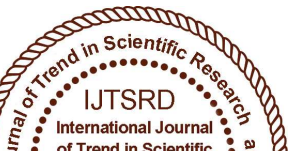 & $\begin{array}{l}\text { International Journal of Trend in Scientific } \\
\text { Research and Development (IJTSRD) }\end{array}$ \\
\hline $\begin{array}{lll} & \\
0\end{array}$ & International Open Access Journal \\
\hline 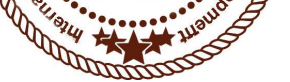 & ISSN No: $2456-6470$ | www.ijtsrd.com | Volume - 2 | Issue -3 \\
\hline
\end{tabular}

\title{
Impact of Job Satisfaction on Employee Retention of IT Professionals
}

\author{
Dr. V. M. Anitha Rajathi \\ Assistant Professor, Department of Management \\ Studies, Anna University(BIT- campus), \\ Tiruchirappalli, Tamil Nadu, India
}

\begin{abstract}
Pavithra. P
PG Student, Department of Management Studies, Anna University(BIT- campus), Tiruchirappalli, Tamil Nadu, India
\end{abstract}

\section{ABSTRACT}

Human resources are the source of revenue of all types of an organization. The major challenge that organizations are facing today is not only managing these resources but also retaining them. Securing and retaining experienced employees plays an important task in any organization, because employees acquaintance and skills are vital to companies ability to be competitive cost-effectively. This paper focusing on employee satisfaction can positively impact the organization as it increases the productivity, performance, quality of work, profits \& dedication to the organization, reduced turnover, superior attendance. Thus, this paper seeks to look at the impact of job satisfaction on employee retention of information technology professionals specifically the software engineers.

Keywords: job satisfaction, employee retention, productivity, performance

\section{INTRODUCTION}

Human resources are the people who formulate up the employees of an organization, for business economy. Human capital is occasionally used synonymously with human resources. It is difficult for the organization to compete in the current era of competition without the reliable and competent Human Resource. Employee retention refers to the capability of an organization to keep hold of its employees. Employee retention can be represent by a uncomplicated statistic. However, may consider employee retention as performance to the efforts by which employers effort to sustain employees in their workforce. In this sense, retention becomes the
Strategies slightly than the outcome. Employee satisfaction refers to a anthology of positive and/or negative opinion that an individual holds toward his or her job. It is the quantity of satisfaction connected with a job. Job Satisfaction is an expressive response to a job. Job satisfaction has been studied both as a consequence of many individual and work environment characteristics and as an antecedent to many outcomes. Employees who have higher job satisfaction are usually less absent, less likely to leave, more productive, more likely to display organizational commitment, and more likely to be satisfied with their lives.

There are a variety of factors that can influence a person's level of job satisfaction. Some of these factors include the level of pay and benefits, the perceived fairness of the promotion system within a company, the quality of the working conditions, leadership and social relationships, the job itself (the variety of tasks involved, the interest and challenge the job generates, and the clarity of the job description/requirements). The happier people are within their job, the more satisfied they are said to be. The concept of job satisfaction has gained importance ever since the human relations approach has become popular. Job satisfaction involves complex number of variables, conditions, feelings and behavioural tendencies.

\section{LITERATURE REVIEW:}

[Locke, 1976]. In other words, job satisfaction, it is satisfying emotional state as a result of damage 
assessment of the occupation or the experience of a job.

[Arnold and Feldman,(1996)]. shows that factors such as tempera- ture, lighting, ventilation, hygiene, noise, working hours, and resources are all part of working conditions. Employees may feel that poor working conditions will only provoke negative performance, since their jobs are mentally and physically demanding.

[Spector, (1997)]. refers to job satisfaction in terms of how people feel about their jobs and different aspects of their jobs.

[Mulinge and Mullier, (1998)]. Lower convenience costs, higher organizational and social and intrinsic reward will increase job satisfaction

[Chang, (1999)]. It is widely used in the field of human resources, who thought that the internal and external features are elements work satisfaction reports

[DeYoung (2000)]. One of the core concepts in Human Resources literature for employers is the retention and development of the human capital to facilitate a competitive advantage

[Vidal, Valle and Aragón, (2007)]. Job satisfaction is complex phenomenon with multi facets and influenced by the factors like salary, working environment, autonomy, communication, and organizational commitment

[According to Horwitz (2008)]. skills shortages are a threat to economic growth. He argues that retention strategies are critical in a global market that is faced with the shortage of skilled workers. The skills shortage challenge is not a South African phenomenon alone. It is therefore important for business, government public and private sector leaders to address this critical component of employee retention for competitiveness and service delivery.

[Coetzee and Schreuder (2013)]. argue it is therefore important that organisations have both hygiene factors and motivation factors to keep their employees satisfied so that they will not leave the organisation. Motivation factors are often said to lead to high retention but the absence of hygiene factors may result in increased turnover.

\section{OBJECTIVES OF THE STUDY}

1. To identify the methods adopted by organization which helps the employee retention.

2. To explore the relation between various factors of job satisfaction and employee retention

3. To suggest and recommend some measures to improve employee retention strategies.

\section{IMPORTANCE OF EMPLOYEE SATISFACTION}

1. Employee satisfaction is of utmost importance for employees to remain happy and also deliver their level best. Satisfied employees are the ones who are extremely loyal towards their organization and stick to it even in the worst scenario.

2. The first benefit of employee satisfaction is that individuals hardly think of leaving their current jobs.

3. Employee satisfaction is essential to ensure higher revenues for the organization

4. Satisfied employees tend to adjust more and handle pressure with ease as compared to frustrated ones.

\section{FACTORS AFFECTING \\ SATISFACTION \\ WORKING CONDITIONS}

Because employees spend so much time in their work environment each week, it's important for companies to try to optimize working conditions. Such things as providing spacious work areas rather than cramped ones, adequate lighting and comfortable work stations contribute to favourable work conditions. Providing productivity tools such as upgraded information technology to help employees accomplish tasks more efficiently contributes to job satisfaction as well.

\section{OPPORTUNITY FOR ADVANCEMENT}

Employees are more satisfied with their current job if they see a path available to move up the ranks in the company and be given more responsibility and along with it higher compensation. Many companies encourage employees to acquire more advanced skills which will lead to the chance of promotion. Companies often pay the cost of tuition for employees taking university courses, for example. During an employee's annual performance review, a supervisor 
International Journal of Trend in Scientific Research and Development (IJTSRD) ISSN: 2456-6470

should map out a path showing her what she needs to accomplish and what new skills she needs to develop in order to be on a track to advancement within the organization.

\section{WORKLOAD AND STRESS LEVEL}

Dealing with a workload that is far too heavy and deadlines that are impossible to reach can cause job satisfaction to erode for even the most dedicated employee. Falling short of deadlines results in conflict between employees and supervisors and raises the stress level of the workplace. Many times, this environment is caused by ineffective management and poor planning. The office operates in a crisis mode because supervisors don't allow enough time for employees to perform their assigned tasks effectively or because staff levels are inadequate.

\section{RESPECT FROM CO-WORKERS}

Employees seek to be treated with respect by those they work with. A hostile work environment -- with rude or unpleasant co-workers -- is one that usually has lower job satisfaction. In an August 2011 survey published by FoxBusiness.com, 50 percent of those responding said they had personally experienced a great amount of workplace incivility. Fifty percent also believe morale is poor where they work. Managers need to step in and mediate conflicts before they escalate into more serious problems requiring disciplinary action. Employees may need to be reminded what behaviours are considered inappropriate when interacting with co workers.

\section{RELATIONSHIP WITH SUPERVISORS}

Effective managers know their employees need recognition and praise for their efforts and accomplishments. Employees also need to know their supervisor's door is always open for them to discuss any concerns they have that are affecting their ability to do their jobs effectively and impeding their satisfaction at the office.

\section{FINANCIAL REWARDS}

Job satisfaction is impacted by an employee's views about the fairness of the company wage scale as well as the current compensation she may be receiving. Companies need to have a mechanism in place to evaluate employee performance and provide increase salary to top performers. Opportunities to earn special incentives, such as bonuses, extra paid time off or vacations, also bring excitement and higher job satisfaction to the workplace.

\section{HOW TO IMPROVE EMPLOYEE SATISFACTION?}

Employee attitudes typically reflect the moral of the company. In areas of customer service and sales, happy employees are extremely important because they represent the company to the public.

\section{1. lucid, succinct and Consistent Communication:}

In many organizations, employee doesn't know what is mission, vision, objects. Building a corporate culture that requires employees to be an integral part of the organization can be an effective way of getting the most from the talents or competencies brought to the organization by each employee. We should keep employees informed on the company's position, progress made, issues/challenges, and how they directly contribute to the success of the business.

2. Getting to Know Your Employees and Create a Team: It can be done by hiring the right employee for right job and clearly defined and communicated employee expectations. Every organization should spend time to instill trust and accountability, laying out clear expectation and securing their commitment to the business and build a culture around working together to meet challenges, create new advantage, and propel the business to greater success.

3. Training and Other Improvement Programs: Provide necessary education, training and coaching that increases employees skills and shows the employee that you are interested in their success and readiness for new responsibility.

4. Empower Employees Across the Company: Step up appropriate levels of new responsibility across the company. Push appropriate decision making and allow people closes to the issue to make the call. Make sure your employee knows that you trust them to do their job to the best of their ability.

5. Work Itself: We can increase employee satisfaction by making job rotation, job enlargement like knowledge enlargement and task enlargement as well as job enrichment. Target should be accessible for employee.

6. Fair Compensation and Benefits: Policies of compensation and benefits are most important part of organization. But you should build your policies at "suitability" not "the best".

7. Opportunity for Promotion and Career Development: Develop programs to promote all titles in the organization and build programs for career 
development of each title. Organization should give opportunity to every employee for using their abilities, skills and creativeness.

\section{Monitor Performance and Reward for} Contribution: People naturally keep score. Use this as advantage by monitoring positive contribution and behavior, rewarding as appropriate. Motivate others to reach new performance levels by knowing how they measure upto expectation. We should build the proper evaluation and fair and encourage employees perform work.

9. Provide Regular, Honest Feedback: Don't wait for a crisis situation to give feedback. Instead, give regular constructive input into the employee's performance across a wide variety of issues, build loyalty, challenge to new levels of performance and keep it real.

10. Provide Best Equipment and Safe Working Condition: Invest in employees by making sure their tools and equipments don't keep them from being successful. Give them the very best tools to deliver the very best performance to the company, customers and the marketplace. Companies should build occupational health and safety program.

\section{CONCLUSION}

Job satisfaction affects retention of employees. As when any component of job satisfaction is troubled it will directly affect the employee turnover. Focusing on employee satisfaction can positively impact the organization as it increases employee productivity, performance, quality of work, profits, commitment to the organization and reduces turnover and absenteeism. In IT sector nature of job is stress and compressed and doesn't provide scope to interact with other colleagues and peers. As a result employees leave the organization to grab the better opportunities. The employees are also dissatisfied with the appraisal system. It is suggested that the IT industry should made the curtail attrition and must come up with innovative strategies to retain the employees.

\section{REFERENCES}

1) Bartolo, K. \& Furlonger, B. (1999), Leadership and job satisfaction among aviation fire fighters in Australia, Journal of Managerial Psychology, 15, 87-97.

2) Wetprasit, P. (2006), Impact of work-related determinants on job satisfaction and retention intentions in Thai spa industry, Unpublished $\mathrm{PhD}$. Dissertation.

3) Velso R.F.E., Silva D.C.R., Dutra S.J., Fischer L.A. \&Trevisan N.L. (2014) "Talent Retention Strategies in Different Organizational Contexts and Intention of Talents to Remain in the Company", Journal on Innovation and Sustainability, vol. 5, ISSN: 2179-3565, pp.49-61

4) 4. Dhamodharan V. \&Elayaraja K. (2013) "Impact of Job Satisfaction and Organizational Commitment on Employee Talent Retention in ITES Organization of Chennai", International Journal of Logistics \& Supply Chain Management Perspectives, vol. 2, No. 4, ISSN: 2319-9040, pp. 682-686 In
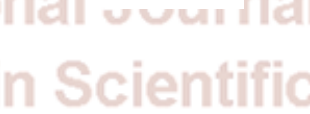

\section{rch anc}

